\title{
Impact of Globalization of Education and Dynamics of Social Changes in Pakistan: Attitude Scale Construction and Analysis
}

\author{
Alyas Qadeer Tahir \\ National Institute of Science and Technical Education \\ Sector H-8/1, Islamabad, Pakistan \\ Tel: 92-51-925-0538Ｅ-mail: ilyasqadeer@yahoo.com
}

\begin{abstract}
Globalization has been largely influenced and spread due to advancement of technology of communication. There has been emphasis in developing countries to seek public opinion on various aspects of globalization. The trend of globalization has opened up doors for country like Pakistan to explore opinion of its intellectuals on this particular dimension. A study was conducted on this particular issue of international importance. For this purpose, a scale was constructed on the attitude of professors of universities, educationists and the members of Chamber of Commerce and Industries of Pakistan. Initially, a likert scale of twenty five items was constructed and tried out to the respondents. After a comprehensive analysis, the scale was redefined and cut down to sixteen items for administration at larger scale at national level. This study provided an ample opportunity for item's analysis and exploring the opinions about globalization of education and perspectives of social changes. It was found that respondents generally look in favor of globalization. The result of the t-test showed that no statistically difference exist between opinion of the university professors and educationists whereas there was a statistically significant differences noted between university professors and members of Chambers of Commerce and Industries and similarly between the opinion of educationists and the members of Chamber of Commerce and Industries. There was statistical significance noted at $\mathrm{p}<0.05$ level in academic performance for the two groups $F(1.58)=$ $5.5351 \mathrm{p}=.001$ as result of one-way ANOVA. A two-way between-groups ANOVA was also conducted to see the impact of globalization on university professor's subjects they teach in the category of management sciences, economics/commerce, and natural sciences and the years of experiences they possess. The interaction effect between the subject they teach and their experience was not statistically significant, $F(3,94)=.563, \mathrm{p}=.471$. The main effect for the subject areas, $F(3,96)=.152, \mathrm{p}=.736$; and the experience of professors possess,

$F(3,96)=1.241, \mathrm{p}=.138$ did not reach the statistical significance. The results of the study can be viewed in Pakistani perspectives and need to be explored further in regional context.
\end{abstract}

Keywords: Scale construction, Item analysis, Globalization, Social changes 


\section{Introduction}

Globalization is not a new phenomenon for this region of the world. The British entered in the area of sub-continent with the purpose of trade in early years of $18^{\text {th }}$ century (Rasool, 1989). However, the process has speeded up dramatically in the last two decades as technological advances made it easier for people to travel, communicate and do business internationally, quickly and efficiently (Heath, Fisher \& Smith, 2005). A massive spread of education and western-oriented norms of learning at all levels of social life has accelerated the process of measuring attitudes of stakeholders on particular dimension (Ahmad, 2007). There is some direct intervention in the governance of national educational systems by trans-national agencies such as the IMF and the World Bank, the impact of globalization is most felt through the extent to which politics everywhere are now essentially market-driven (Leys, 2001). Samoff (1994) stated that "observers have reported that structural adjustment politics often encourage an emphasis on inappropriate skills reproduce existing social and economic inequalities, leading actually to lowered enrollment rates, an erosion in the quality of education and a misalignment between educational need and provision”.

One of the most popular methods of measuring attitudes is the method of summated ratings, commonly referred to as the Likert-type scale. The Likert-type scale has been used by persuasive researchers for over three decades. The original scale of this type was developed by Rensis Likert and is explained in his article, "A Technique for the Measurement of Attitudes," in Achieves of Psychology (1932). He reported very satisfactory reliability data for the scales developed with his procedure. In addition, Likert reported that results obtained from his scales compared favorably with those obtained by the "granddaddy" of the attitude scales-the Thurstone scale. Subsequent research has generally confirmed the fact that the Likert-type attitude scales are quite reliable and valid instruments for the measurement of attitude.

\section{Literature Review}

There have been a few studies conducted on opinion of various dimensions of globalization. It has been reported on a Website:www.americans-world.org/digest/global uses that when asked about the term "globalization" but given no context or definition, attitudes are more positive. In September 2002, few poll found a solid majority of $62 \%$ saying it was a "very good" (10\%) or "somewhat good" 52\% thing. Only 23\% said it was bad. In 2004, 40\% rated globalization above 5, while just $19 \%$ rated it below 5, and $39 \%$ rated it at 5, i.e., equally positive and negative. In the 1999 poll, a modest majority of 53\% rated it above 5, suggesting attitudes have cooled slightly in the past few years. In PIPA's January 2004 poll, respondents were given a very broad definition of globalization that included economics, communication, travel and culture. Then they were asked to rate globalization using a scale with zero being completely negative, ten being completely positive and five being equally positive and negative. The average response was 5.62, down a bit from when PIPA asked this question in October 1999 and found a mean response of 6.04.

An article was published in Family and Consumer Science Research Journal (2009) by Warren and others entitled Moderator effects on attitude scale construction. Data from study 
on smoking and health was used to examine three methodological questions: (1) does the method of scale construction influence the items in the resultant scales? (2) do alternate subgroup delineations influence the formulation of scales? (3) if different scales are formed, what are the measurement criteria such as reliability, inter-item and item-total correlations and statistical testing? Cluster analysis and theory were used to formulate the scales. The study provided empirical support that (1) the method used to construct scales and (2) the moderators or subgroups do influence items with scales, measurement criteria and statistical testing. In a study conducted by Munsell (2004), 203 college students were recruited to help determine clarity and precision on the wording of four items in the Templer, Salter, Baldwin, Dickey and Veleter (1981) Pet Attitude Scale (PAS). The item analysis showed that correlation with total score did not differ for three of the pairs of items. For one of the items, the correlation was higher with the original wording. The 18-itm Pet Attitude Scale Modified retains the original wording for that item and uses the modified wording for the other three items.

In a study carried out by Reifler (2009) on globalization attitude, global consumption orientation and global brand perception, he used five items from Spears et al (2004) globalization attitude showed a positive impact on global brand evaluations. The construction of globalization attitude was delineated.A study was undertaken by Raza (2002) on global village and changing international attitude. The researches used International Reaction (IR) and Everyday Reaction (ER) scales for testing hypothesis. The subjects were asked to perform a similarly Judgment Job of rating sixteen selected nations on a similarity scale and responded to questions pertaining to interpersonal and international situations in the form of a questionnaire. The study provided an opportunity for correctional analysis and improving the scales for further research. A paper was published by Woodword and others (2008) in British Journal of Sociology on attitude towards globalization and cosmopolitanism. The researchers used data from a representative Social Survey Australians. The data tap into attitude and behaviors associated with a broad gamut of cosmopolitan traits in the domain of culture, consumption, human rights, citizenship and international governance. The analysis of data on attitude towards globalization and cosmopolitanism provided prospects for constructed a bridged scale. Suh and smith (2008) have concluded that "empirical studies testing impact of globalization have not met with mixed results possibly due to the effects of globalization accruing at different levels in the mind-sets among consumers. The researchers have found positive attitude toward globalization and subsequent global openness”.

\section{Selection of an Attitudinal Object-Definition \& Rationale}

The attitudinal object chosen for this study was about "Globalization of Education and Dynamics of Social Changes in Pakistan”. The attitudinal object was selected for two reasons. First, globalization of education is not a broad topic for constructing an attitudinal scale in Pakistani's perspectives the relatively narrow scope could prevent respondents from having multiple dimensions in attitudes. According to Mueller (1986), the measurement effort is more successful if the attitudinal object is clearly delimited. Second, if the respondents do not know anything about what is being measured, it is difficult for them to take a stand. Then, most of them are likely to remain neutral and there will not be much spread in attitudes. It 
was anticipated that respondents would know something about Globalization of Education and Dynamics of Social Changes but is rather not very common in Pakistan. It turned out that the respondents did seem knowledgeable about this attitudinal object.

\section{Construction of the Attitudinal Scale}

\subsection{Generating Item Pool}

In this study, Likert attitude scaling techniques were employed. Twenty-five items were initially generated. Twelve items were coded positive; thirteen negative. These items are beliefs or opinions about Globalization of Education and Dynamics of Social Changes in Pakistan. In writing these items, an effort was made to make the opinions or beliefs statements simple and straight forward as possible, without multiple connotations or ambiguity. An expert in scale construction was consulted on the first draft. Diversity of opinions was taken into consideration. Different aspects of Globalization of Education and Dynamics of Social Changes such as trade, security concerns, economical influence, religious values and cultural heritage were included in the scale.

\subsection{Administration and Scoring}

The scale was administered to 38 subjects at tried out stage. All of them were university professors and educationists. Originally, it was intended to use the known-group method of validation, but it was difficult to find out who is aware of the particular dimension or not. Further, even if people dislike it, they will probably portend they do when asked, because "people are socialized to be agreeable and to agree” (Mueller, 1986). So, as a compromise, some scale forms were administered to a small group of respondents of twin cities. It was anticipated that this group would have a favorable attitude as all of the subjects were professors and educationists. The possibility of finding out the unfavorable attitude had to be left to chance. One sure thing about the administration was that all subjects showed a great cooperation and returned all the forms. None of the forms was randomly rated and, so were all included in the final analysis.

Five Likert response categories were used in the scale. They were "strongly agree”, "agree”, "uncertain”, “disagree”, and "strongly disagree”. In items keyed positive, “strongly agree” received 5 points, "agree" 4 points, and so on. For negatively-keyed items, the scoring was reversed, that is, "strongly agree” received 1 point, “agree” 2 points, and so on. The highest possible score for each item was 125 points ( 5 x 25 items); the lowest was 25 . The highest score was interpreted as a strongly positive attitude whiles the lowest, a strongly negative attitude.

\section{Analysis}

The items were analyzed by a statistical reliability program. The statistical information about each item included item's means, standard derivations and items correlations with total score. The alpha reliability coefficient for the scale was also worked out (Table 1). The item's means and standard deviations tell about the response distribution and spread in attitudes. The correlation coefficient is used to find out whether the items discriminate well. The 
discrimination of each item contributes to the reliability of the scale. If the scale is reliable, it is measuring consistently and accurately, rather than randomly (Mueller, 1986). The scale had an alpha reliability of .7123. Twenty items correlated positively with the

Table 1. Opinions about Globalization of Education and Dynamics of Social Changes in Pakistan

Reliability Analysis

\begin{tabular}{|c|c|c|c|c|c|}
\hline Item No. & $\begin{array}{l}\text { Positive or } \\
\text { negative }\end{array}$ & Mean & $\begin{array}{l}\text { Standard } \\
\text { Deviation }\end{array}$ & $\begin{array}{l}\text { r with } 25 \text { item } \\
\text { scale }\end{array}$ & $\begin{array}{l}\text { r with } 16 \text { item } \\
\text { scale }\end{array}$ \\
\hline 01 & $\mathrm{P}$ & 3.3824 & .8533 & -.0647 & - \\
\hline 02 & $\mathrm{P}$ & 4.0294 & .9688 & .3989 & .38229 \\
\hline 03 & $\mathrm{~N}$ & 4.1471 & .6575 & .6166 & .5536 \\
\hline 04 & $\mathrm{P}$ & 3.1417 & 1.2094 & -.0194 & - \\
\hline 05 & $\mathrm{P}$ & 4.5588 & .6602 & .4085 & .3641 \\
\hline 06 & $\mathrm{P}$ & 2.6471 & .8121 & -.2894 & - \\
\hline 07 & $\mathrm{~N}$ & 3.2059 & 1.0380 & .3024 & - \\
\hline 08 & $\mathrm{~N}$ & 4.2941 & .9384 & .3779 & .4025 \\
\hline 09 & $\mathrm{~N}$ & 3.9118 & .8300 & .5679 & .6235 \\
\hline 10 & $\mathrm{P}$ & 4.5588 & .6126 & .5241 & .5574 \\
\hline 11 & $\mathrm{~N}$ & 3.5294 & .9919 & .4622 & .5065 \\
\hline 12 & $\mathrm{P}$ & 2.7353 & .9312 & -.2468 & - \\
\hline 13 & $\mathrm{P}$ & 2.9706 & .9040 & -.2311 & - \\
\hline 14 & $\mathrm{~N}$ & 3.1471 & .7440 & .0934 & - \\
\hline 15 & $\mathrm{P}$ & 3.9118 & .8300 & .4640 & .5339 \\
\hline 16 & $\mathrm{~N}$ & 4.1176 & .9134 & .5091 & .4923 \\
\hline 17 & $\mathrm{P}$ & 4.0882 & .9651 & .6231 & .6404 \\
\hline 18 & $\mathrm{~N}$ & 4.4412 & .6602 & .4124 & .4358 \\
\hline 19 & $\mathrm{~N}$ & 3.7647 & .8187 & .4737 & .5476 \\
\hline 20 & $\mathrm{~N}$ & 4.1765 & .9365 & ,5178 & .5409 \\
\hline 21 & $\mathrm{~N}$ & 4.2353 & .7808 & .4058 & .4499 \\
\hline 22 & $\mathrm{~N}$ & 3.2647 & 1.0534 & .4104 & - \\
\hline 23 & $\mathrm{~N}$ & 4.0000 & .8165 & .2694 & .2940 \\
\hline 24 & $\mathrm{P}$ & 3.9412 & .7762 & .385 & .4312 \\
\hline 25 & $\mathrm{P}$ & 2.2059 & 1.2005 & .0864 & - \\
\hline
\end{tabular}

total scale sector. However, six items correlated negatively. These items are listed and discussed as under:

Item 1 Globalization is not good for Pakistan where there is increase exploitation of child labour. (-.06).

Item 4 Globalization symbolizes an umbrella to all civilizations (-.01) 
Item 6 Pakistani’s got influence of globalization more than any country of the region. (-.28)

Item 12 Our social values have gone down due to globalization. (-.24)

Item 13 Globalization can help Pakistan to strengthen the weak economic conditions (-.23).

Item 22 Globalization is not widely acceptable. (1.41)

First five items were keyed positive and all correlated negatively. Whereas the last item was keyed negative but was correlated positively. The correlation for item 1 was -.06. The mean was 3.38, showing that respondents are on higher side of the statement. Re-reading of the item showed that the item may be positive for anti-human rights but not for pro-human rights.

The item 4 has mean of 3.14 indicated that the respondents attitude learnt towards the positive side in spite of the fact that the respondents' attitudes were spread out. The standard deviation of the item was 1.20, the highest of all items in the study. However, the correlation was -.019. When rechecked the key and coding on the output of the program, it was found nothing wrong with them. Re-reading of the item showed that it was probably worded too strongly. Globalization may be good for some civilization like western but not necessarily to be equally good for Pakistani's and some other civilizations of the world. A possible explanation for this unusual result could be that the professors and educationists of Pakistani's colleges and universities may have chosen either "strongly agree” or "agree”. The respondents may be not very much exposed to the negative effects of globalization on various civilizations of the world. This item was ultimately dropped before administration of the scale.

Item 6, 12 and 13 suggest the similar type of meaning. Item 6, with a mean of 2.64 indicated that respondents tended to disagree. Item 12 had a mean of 2.73 indicated that respondents tended to disagree. Item 13 had a mean of 2.97 again indicated that respondents tended to disagree. In all these three items, the largest percentage of responses for each remained "uncertain" and the means did not dramatically deviate from points. Re-reading of these items revealed that for such kind of statements, it is really hard of the respondents to take a decision. No matter what they thought of globalization, they just could not decide whether the globalization could influence social values of Pakistan's, gone down due to globalization or this had strengthen the economical condition of Pakistan.

Item 22 was keyed as negative item but correlated positively which was 0.41 . The distribution data showed that the respondents tended to agree (mean=3.26). The positive correlation could mean that the item was very much clear. To some respondents, globalization is widely acceptable or nearly acceptable; to others it might be the opposite.

The mean score for the 38 respondents was 92.4066. This indicates that the sample group was very positive in its attitude towards globalization, since if everyone had remained "uncertain" the mean would have been 75 (3x25). If the scale was going to be redefined and both positive and negative items were to be balanced, the result was expected to change. 


\section{Redefining the Scale}

According to Mueller (1986), if the item correlates high with the total scale score, it discriminates among respondents. On the other hand, a zero or near zero correlation indicates that the item does not discriminate among respondents the way the total score does. Such an item is not measuring the same thing that other items are measuring and should be eliminated from the scale. Also if negatively correlated items are working against the discrimination, these items are also be eliminated. Since in this study, some items were positive ones and some of the negative items with low correlation co-efficient, they had to eliminate too for balance. As a result, the initial 25 items are cut down to 16 items and a bridged scale was ready to administer at mass level in Pakistan. The bridged scale was analyzed using the same computer program. The alpha reliability coefficient rose from the 0.7123 to 0.8435 . According to Mueller (1986), this is very high and is one indication that the scale was well constructed.

\section{Methodology and Data}

Sixteen items were finally retained in the bridged scale with half each positive and negative used for data collection at national level. The scale was administered to random sample of 100 subjects. Among these, 60 were university professors, 30 educationists and 10, the members of Chamber of Commerce and Industries of Pakistan. Five Likert response categories were used in the scale. They were "strongly agree”, “agree”, “uncertain”, "disagree”, and "strongly disagree”. In items keyed positive, "strongly agree” received 5 points, “agree” 4 points, and so on. For negatively-keyed items, the scoring was reversed, that is, "strongly agree" received 1 point, "agree" 2 points, and so on. The highest possible score for each item was 80 points ( $5 \times 16$ items); the lowest was 16 . The highest score was interpreted as strongly positive attitudes while the lowest, a strongly negative attitude. The independent variables were quantified on the chosen scale through face validity, content validity and consensus of the study team using an analytical-cum-judgmental technique (Wiseman and Pidgeon, 1970). The reliability coefficient of the scale was found to be 0.8435 . The data was collected using the stratified sampling techniques by covering major and minor urban Universities, renowned educationist and the senior members of Chamber of Commerce and Industries of Pakistan. The data was analyzed through using SPSS software to give statistical treatment for multiple regression analysis, t-test and two-way ANOVA tests.

\section{Results and Discussion}

In the final scale, the sixteen items served as dependent variables whereas the globalization impact referred as independent variable of the study. The value of $\mathrm{R}$ Square worked out for regression analysis found to be .817 showing that dependent variables have strong (98.7\%) impact on globalization. The table value of coefficients came up as positive showing that dependent variables have positive impact on globalization and dynamics of social change in Pakistan. T-test was applied to research questions; is there a mean difference between opinion of university professors (group 1), educationists (group 2) and senior members of Chambers of Commerce and Industries (group 3) exist?. The result of the test showed that no statistically differences exist between opinion of university professors and educations 
whereas there is a statistically significant differences noted between university professors and members of Chambers of Commerce and Industries and similarly between the opinion of educations and the members of Chambers of Commerce and Industries. The Levene's test for equality of variances showed that variances between groups 1 and 2 are not equal as significance value (.04) is less than the confidence level, 0.05. The significance (2-tailed) value is .816 which is greater than .05 indicated that there is no significance difference between opinion of university professors and educationists. For the groups 1 and 3, the Levene's test for equality of variances showed that variances between group 1 and group 3 are same as significance value (.214) is greater than the confidence level, 0.05 . The significance (2-tailed) value .04 which is less than .05 showing that there is a significant difference between opinion of university professors and the members of Chambers of Commerce and Industries. Similarly, for the groups 2 and 3 , the Levene's test for equality of variances showed that variances between group 2 and group 3 are same as significance value (.134) is greater than the confidence level, 0.05 . The significance (2-tailed) value .01 which is less than .05 showing that there is a significant difference between opinion of educationists and the members of Chambers of Commerce and Industries.

One-way ANOVA was applied to seek the answer to the research question, is there significant difference on impact of globalization of education and dynamics of social changes of university professors belonging to major urban and minor urban areas of Pakistan? The significance value in Levene's test for homogeneity of variances found to be .264 which is greater than the level of significance (.05) showing that no violation is made in respect of assumption of homogeneity of variances. The one-way ANOVA between groups analysis of variances was conducted to examine the impact of globalization of education and dynamics of social changes of university professors belonging to major urban and minor urban areas of Pakistan. Accordingly, the subjects were divided into groups of professors of universities situated in major cities and minor cities of Pakistan. There was statistical significance noted at the $\mathrm{p}<0.05$ level in academic performance for the two groups $F(1,58)=5.351 \mathrm{p}=.001$

A two-way between-groups ANOVA was conducted to see the impact of globalization on university professor's subjects they teach in the category of management sciences, economics/commerce, and natural sciences and the years of experiences they possess. The interaction effect between the subject they teach and their experience was not statistically significant, $F(3,94)=.563, \mathrm{p}=.471$. The main effect for the subject areas, $F(3,96)=.152, \mathrm{p}$ $=.736$; and the experience of professors possess, $F(3,96)=1.241, \mathrm{p}=.138$ did not reach the statistical significance.

The results of the study showed statistical difference on impact of globalization and dynamics of social changes of university professors belonging to major and minor urban areas of Pakistan. This indicates that Pakistani professors of universities of major urban cities have different perception than those belong to the universities situated in minor urban cities. Perhaps, this is due to difference in exposition to various dynamics of social changes prevailed in major and minor urban cities of Pakistan. This situation can be different in other countries of the region. The study also revealed that there was no statistical significance found at the $\mathrm{p}>0.05$ level of the subjects universities professors teach and also for the 
teaching experience they possess. It can be speculated that the Pakistani university's professors have the same mind set about Globalization regardless of their status, the years of experience they been teaching. That is why the interaction effect between cadres of university professors and the experience they possess was not statistical significant when measured and the main effect for these two factors did not reach the statistical significant. The results of this study showed that the respondents generally looks in favor of globalization which is consistent with the results found by Woodword (2008).

\section{Conclusion}

This study contributed in three ways. First, an attitude scale was constructed on globalization of education and dynamics of social changes prevailed in Pakistani society. This initial scale set a systematic developmental procedure, validation and reliability of the item scale. Second, the analysis process comprised of working out means, standard deviations and correlation $r$ as statistical measures which were quite enough to help in item-wise analysis and interpretation leading to construct a refined scale. Third, statistically determined the impact of globalization and dynamics of social changes while using the bridged scale at national level. A number of research questions were addressed in this section following interesting findings and results. Further, research studies can be carried out to extend the present study into a large set of measurable variables of globalization influencing the education sector of Pakistan and the countries of the region. As matter of fact "it is time to recognize that the true tutors of our children are not school's teachers or university professors but filmmakers, advertising executives and pop purveyor. Disney does more than Duke, Spielberg outweighs Stanford, MTV trumps MIT" (Benjamin R. Barber quoted by Giroux 2000:15 in Smith's article of 2002).

\section{References}

Ahmad, Nazir. (2006). Social Dimension of Pakistani Society. Journal of Elementary Education, 17(1), 32-37.

Alden, D.L., Steenkamp, J.B., \& Batra, r. (2006). Consumer Attitudes toward market place globalization: Structure, Antecedents and Consequences. International Journal of Research in Marketing, 23(3), 227-239.

American Psychological Association. (1985). Standards for Educational \& Psychological Tests. American Psychological Association, Inc. Washington, D.C

Heath. A, Fisher, S \& Smith, S. (2005). The Globalization of Public Opinion Research. Annual Review of Political Sciences, Vol. 8, U.K.

Hopkins, K., Stanley, J., \& Hopkins, B. (1990). Educational and Psychological Measurement and Evaluation, ( $7^{\text {th }}$ ed.) English Cliffs, New Jersey: Prentice Hall.

Leys, C. (2001). Market Driven Politics. Neoliberal democracy and the public interest, London: Verso Books. 
Mueller, D.J. (1986). Measuring Social Attitude. A hand book for the Researchers \& practitioner, New York, Teachers college press.

Munsell, KL. (2004). Modification of the Pet Attitude Scale. Society of Animal Journal 12(2), Koninklijke Brill NV, Leiden.

Rasool, Sahibzada Abdul. (1989). Tareekh-e-Pakistan, IMR Brothers, Lahore.

Raza, Amera. (2002). The Global Village and Changing International Attitudes (Unpublished). NEP, Islamabad.

Riefler, Petera. (2009). Global attitude, Global consumption orientation and Gloabla Brand Percsptions (unpublished). University of Bruenner Strasse, Austria.

Samoff, Joel, ed. (1994). Coping with Crisis: Austerity, Adjustment, and Human Resources. London: Cassell.

Smith, M.K. (2002). Globalization and the incorporation of education. The encyclopedia of informal education, [Online] Available: www.infed.org/biblio/globalization.htm.

Spears, M.C., Parker, F., \& McDonald, M. (2004). Globalization attitudes and locus of control. Journal of Global Business, 15(29), 57-64.

Suh, Taewon and Smith, Karen H. (2008). Attitude toward Globalization and Country-of-Origin Evaluations: Toward a Dynamic Theory. Journal of Global Marketing, 21(2): 127-139.

Templer, D.I., Salter, C.A., Dickey, S., Baldwin, R \& Veleber, D.M. (1981). The Construction of Pet Attitude Scale. Psychological Record, 31, 343-348.

Thorndike, R.M, Cunninghan, G.K, Thordike, R.L., and Hagen, E.P. (1991). Measurement and Evaluation in Psychology and Education. New York, Macnollan publishing company.

Warren, R.D., Mulford, C.L \& Winkelpleck, J.M. (2009). Moderate Effects on Attitude Scale Construction. Family and consumer Research Journal, 1(14), USA

Wiseman, S., and Pidgeon, D. (1970). Curriculum Evaluation. NFER, Slough.

Woodword I., Skrbis, Z., \& Bean, C. (2008). Attitudes towards globalization and cosmopolitanism: cultural diversity, personal consumption and the national economy. The British Journal of Sociology, 59(2), UK.

[Online] Available: www.americans-world.org/digest/global_uses.

\section{Copyright Disclaimer}

Copyright reserved by the author(s).

This article is an open-access article distributed under the terms and conditions of the Creative Commons Attribution license (http://creativecommons.org/licenses/by/3.0/). 